\title{
Social Work Education in the Shadow of Confederate Statues and the Specter of White Supremacy
}

\author{
Travis Albritton \\ Charity S. Watkins \\ Allison De Marco \\ JP Przewoznik \\ Andrew Heil
}

\begin{abstract}
Driven by our code of ethics and our call to reckon with our embeddedness within a white supremacist institution in the US South, the UNC-Chapel Hill School of Social Work re-visioned our approach to the MSW curriculum. Using case study methods, we trace our history and on-going work through interviews, document review, and community conversations, centering student voices. Students interviewed spoke about activism prompted by racist events on campus and nationally, and the inadequate response from the administration. Their efforts led to school-wide initiatives including curriculum shifts and accountability and action. The first-year generalist course, Confronting Oppression and Institutional Discrimination was restructured and resituated. Critical Race Theory was infused across the coursework. Two new working groups were created: The Anti-Racism Task Force and Reconciliation Standing Committee. Efforts to address racism and white supremacy in academic spaces require sustained activism to expose how racism is embedded within our institutions. While much work remains in the practice of becoming an antiracist institution, this model can serve as a prototype for others as they work to create programs that are site-specific and universally reflective of the institutional changes we need.
\end{abstract}

Keywords: Racial justice, social work education, oppression, white supremacy

In keeping with our commitment to anti-oppressive social justice education and practice, and in the shadow of confederate statues and the specter of white supremacy within the ivory tower, the School of Social Work (SSW) at University of North Carolina (UNC)-Chapel Hill embarked on a process to re-vision the way we approach generalist practice in our MSW Program. Our National Association of Social Workers (NASW) Code of Ethics calls on all social workers to work for racial justice and equity (NASW, 2017). This appears in Tenet 1.05, Cultural Competence and Social Diversity:

Social workers should obtain education about and seek to understand the nature of social diversity and oppression with respect to race, ethnicity, national origin, color, sex, sexual orientation, gender identity or expression, age, marital status, political belief, religion, immigration status, and mental or physical disability. (NASW, 2017, para. 22)

\footnotetext{
Travis Albritton, PhD, MSW, Associate Dean for Diversity, Equity, and Inclusion, University of North Carolina (UNC)Chapel Hill School of Social Work, Chapel Hill, NC. Charity S. Watkins, PhD, MSW, Assistant Professor, Department of Social Work, North Carolina Central University, Durham, NC. Allison De Marco, PhD, MSW, Advanced Research Scientist, Frank Porter Graham Child Development Institute and Adjunct Faculty, UNC School of Social Work. JP Przewoznik, MSW, Clinical Assistant Professor, UNC-Chapel Hill School of Social Work, Chapel Hill, NC. Andrew Heil, LCSW, is a Senior Behavioral Wellness Manager, Avance Care, Durham, NC. 
Social and Political Action is addressed in Tenet 6.04:

Social workers should act to prevent and eliminate domination or, exploitation of, and discrimination against any person, group, or class on the basis of race, ethnicity, national origin, color, sex, sexual orientation, gender identity or expression, age, marital status, political belief, religion, immigration status, and mental or physical disability. (NASW, 2017, para. 173)

In 2005, the Social Work Congress developed 12 imperatives to guide the profession over the next decade, which include (Clark et al., 2006):

- Addressing racism, other forms of oppression, social injustice, and other human rights violations through social work education and practice.

- Continuously acknowledging, recognizing, confronting, and addressing racism within social work practice at the individual, agency, and institutional levels.

Our goal is to live into the values of our NASW Code of Ethics and our educational charges from the Council on Social Work Education (CSWE), in which we are called to prepare students to engage diversity and difference in practice and advance human rights, and social, economic, and environmental justice. This work is in service to the vital role that social workers must play in challenging systems of oppression and disrupting white supremacy in our institutions. This article traces the School's re-visioning process, highlighting leadership from students to keep racial and social justice at the forefront, and initiatives to disrupt manifestations of white supremacy culture in our climate and curriculum. Initiatives have targeted all levels of our School community, including SSWwide Community Conversations, faculty trainings, an all-chool retreat, the creation of the Assistant Dean of Diversity, Equity, and Inclusion position, and a faculty and staff book read of How to be an Antiracist by Ibram X. Kendi (Kendi, 2019). Our hallmark educational offerings for students have included an on-line history of oppression course leading into the generalist year and our first-year generalist course, Confronting Oppression and Institutional Discrimination. The School uses Critical Race Theory, along with other seminal critical theories, to frame students' educational journeys and their prospective practice as social workers. This content is introduced in the Confronting Oppression course, which examines institutionalized oppression and implications for practice at all levels, emphasizing the consequences of social inequality and the social worker's responsibilities to interrogate oppression in policy and practice.

\section{Background and Significance}

Since the late 1960s, the CSWE has used Educational Policy and Accreditation Standards (EPAS) to establish guidelines that ensure students in social work programs receive instruction in nine core competencies (CSWE, 2015). The development of EPAS closely mirrors how conversations about issues related to race and diversity have changed over the past 50 years. Jani et al. (2011) point out that as the United States has undergone demographic shifts, CSWE has tried with each new iteration of EPAS to ensure that social work programs remain relevant in their attempts to address issues of diversity and 
difference. Specifically, in 2008 CSWE instituted EPAS Competency 2 which mandates that social work curricula ensure students have opportunities to "engage in diversity and difference in practice" (CSWE, 2015, p. 7). Efforts to fulfill the mandate set forth by EPAS Competency 2 require social work programs to be intentional about instruction in both the explicit and implicit curriculum. The explicit curriculum refers to "the program's formal educational structure and [includes] the courses and field education used for each of its program options" (CSWE, 2015, p. 11). The implicit curriculum refers "to the learning environment in which the explicit curriculum is presented" (CSWE, 2015, p. 14).

Historically, social work education has sought to fulfill such calls for instruction about diversity by exposing students to cultural competency frameworks (Adams et al., 2009; Dreschler et al., 2019; Jani et al., 2011). This emphasis on cultural competence has often been at the expense of more critical models that offer nuanced and expansive approaches to thinking about and understanding issues of diversity, especially with respect to race. As Abrams and Moio (2009) point out, cultural competency frameworks' broad lens with respect to diversity "tend to downplay racism's persistent legacy and leaves social workers unprepared to deal with the realities of racism both systematically and interpersonally" (p. 249).

The decades-long work of students, faculty, and staff within the UNC SSW has led us to a vital moment of reckoning and transition. Members of the SSW community are heeding the call of the current moment while acknowledging that our collective action is far past due, that to be a social worker committed to change in this moment means to acknowledge our decades of complicity and to work against reproducing harm by committing intentionally and sustainably to action. As a site for social work education, we ask ourselves how we affect change from both the inside and outside through our dual charges of acting as social workers in our own right while training up social workers of the future.

This article discusses how one school of social work, when faced with calls from students for more deliberate conversations about the impact of white supremacy in both the school's implicit and explicit curriculum, sought to re-vision the way the school approached generalist practice in the MSW program. In so doing, the authors center student voices to highlight advocacy efforts by students enrolled in the program and discuss how the re-visioning process involved the restructuring of generalist courses, the inclusion of more critical theory in the generalist year, the institution of a summer reading program for newly admitted students, and the creation of an Anti-Racism Task Force.

\section{Method}

Using case study methods, this article traces the School's historical underpinnings and its re-visioning process through interviews, document review, summaries of community conversations, the School's strategic planning process, and initiatives implemented to disrupt manifestations of white supremacy culture in both the climate and curriculum. A case study research approach was selected to enable us to provide an "in-depth understanding of a single or small number of 'cases,' set in their real-world contexts" (e.g., Bromley, 1986, p. 39), here for one school of social work. The goal is to provide a deep 
understanding by describing through various sources the historical and current work to dismantle white supremacy (Yin, 2012). To help frame the history of student activism at the School, we interviewed three former students who were leaders in organizing at the height of this institutional work to highlight their efforts to address issues of racial and social justice, and demands for accountability from the administration and faculty. Semistructured interviews were conducted using virtual conferencing software and lasted about 60 minutes (see Table 1). Questions included perspectives on the School's history of antiBlack racism, students' role in addressing anti-Black racism, impetus for activism, barriers to change during their time as a student activist, wins experienced, and hopes for the future. Interviews were audiotaped and notes taken of key points. Interviews were then transcribed and summarized for key themes. In addition to these key interviews, we reviewed literature from articles written about the School's history, meeting notes, and documents produced during the 2019 - 2020 strategic planning process.

\section{Table 1. Interview Guide}

\section{Questions}

1. [For background] What was/is your role at the School? What years?

2. From your perspective, what is the School's history of anti-Black racism?

3. What was your role in addressing anti-Black racism in the School?

4. What prompted your activism?

5. What were the barriers to change during your time as a student activist?

6. What wins (if any) did you experience?

7. How would you like to see your activism reflected in the School (e.g., student admissions, staff and faculty hiring, acknowledgement of anti-Black racism within the School)?

8. What do you hope for future students of color in the School of Social Work?

\section{A Recent History of Anti-Black Racism}

The history of UNC-Chapel Hill's School of Social Work's anti-Black racism can be explored through the lens of what can be viewed as the difference between the externalfacing and internal-facing stances of the School on issues of racism. The public, externalfacing stance of the School includes being the first department or school at the university to hire an African American faculty member, Professor Hortense McClinton in 1966 (Graham, 2016); and the naming of the SSW building to include Dr. John B. Turner, the first African American dean at UNC Chapel Hill and dean of the School from 1981 to 1992 (Outlaw, 2009). The more private, internal-facing stance includes the underlying evidence of anti-racism that leads to these public demonstrations of racial "wokeness." Such internal-facing illustrations of anti-Black racism includes very little record and recognition of the historic hiring of Professor McClinton (Graham, 2016); a lack of racial diversity among tenured and tenure-track faculty; an extreme lack of representation of people of color among School administration, including Dr. Turner being the first and only Black dean or dean of color within the School's 100-year history; a limited presence of Black students in the school's MSW and PhD programs; and the creation of diversity and inclusion initiatives generally in response to national racial injustices and the racially unjust 
reactions by SSW leadership. In August 2021, Dr. Ramona Denby-Brinson joined the UNC School of Social Work as the first Black female dean of the School. By exploring the external and internal face of the School on issues of racial equity and justice, a publicprivate disparity in the School's promotion of diversity and inclusion are revealed.

\section{The External Face}

Celebrated as the oldest public university in the country, UNC-Chapel Hill first opened its doors to students in 1795, becoming the first and only institution to graduate students in the 18th century (UNC-Chapel Hill, 2020). However, with North Carolina fighting to maintain the right to enslave African people in the Civil War, extending the exploitation of African people and their descendants under the protection of the 13th Amendment during Reconstruction, and continuing the violent oppression of African Americans under the Black Codes and Jim Crow laws, admission to the university was not extended to African Americans until 1951-more than 150 years after Hinton James, UNC-Chapel Hill's first student, stepped foot on campus. Under court order, UNC School of Law and Medical School admitted the first Black male students in 1951, followed by the admission of the first undergraduate Black men in 1955, and the first Black woman in 1963 (UNC-Chapel Hill, 2020).

Although Black students were enrolled at UNC beginning in the 1950s, the racial climate on campus was slow to change. In response to a lag in continued admission of Black students and a lack of representation within curricula, faculty, and student support services, the Black Student Movement (BSM) was formed in the fall of 1967 (The Black Student Movement, n.d.). Within the first two years after its inception, BSM began using activism to shift the campus climate for not only students, but also for staff. In December 1968, BSM presented the chancellor with 23 demands to improve the experiences of Black students on campus including a call for an African American studies department, a campus office centered on addressing the needs of Black students, and equitable admissions policies dependent on grades rather than SAT scores (The Carolina Story: A Virtual Museum of University History, 2019a). A few months later, BSM supported food workers in their month-long strike for fair labor practices by first holding a sit-in at Lenoir Dining Hall followed by more direct student-led action and the walkout of food workers (The Carolina Story: A Virtual Museum of University History, 2019b). BSM's efforts to improve the racial climate of UNC continued in the following decades including: participation in a second food workers' strike near the end of 1969; the protest against the use of student fees to host David Duke-founder of the Knights of the Ku Klux Klan- for an on-campus speaking engagement in 1975; a sit-in at the South Building in 1979 to protest the denial of tenure for Dr. Sonja Haynes, who was the head of African and AfroAmerican studies; a teach-in in October 1990 in protest of the "Student Body" sculpture that portrayed a Black male and female student as stereotypical images (i.e., Black women carrying books on her head, Black man spinning a basketball on his finger); and advocacy for physical space dedicated to Black students on campus including the Sonja Haynes Stone Black Culture Center that opened in 2004 and the rededication of the Upendo Lounge in 2016 as a reserved space for BSM (The Carolina Story: A Virtual Museum of University History, 2019c). 
While long struggling with the legacy of white supremacy as part of the predominately White UNC-Chapel Hill institution, the SSW was leading early on. In 1966, the School hired Hortense McClinton, the first Black faculty member hired at UNC (Graham, 2016). McClinton taught at the School for 20 years, creating and implementing a course on institutional racism in 1972 as well as serving on numerous school and university-wide committees until her retirement in 1984 (Graham, 2016; Moss, 2015). In an interview with UNC's University Archivist, Mrs. McClinton related, "I finally decided, well, if you've been taught a certain thing all your life, you have to learn to know something different. That's when I started the class in institutional racism." Mrs. McClinton also shared that she was tapped to serve on 11 different committees at the same time because "they wanted a black voice, and she was it" (Moss, 2015). Another African American faculty member was not hired by UNC Chapel Hill for another three years; evidence that the SSW was spearheading efforts to desegregate the university beyond student admission (Moss, 2015).

The hiring of Black pioneers on UNC-Chapel Hill's campus continued with the appointment of Dr. John B. Turner as dean in 1981. A Tuskegee Airman during World War II, Dr. Turner became the first Black dean at UNC. During his 11-year tenure, Dr. Turner provided the foundation for the School to become a leader in the field, including the establishment of the School's first development office, advocating for the development of

the doctoral program-the first social work PhD program in North Carolina-and raising the $\$ 10$ million that allowed the SSW to move from five different buildings on the edge of campus to a modern building close to main campus (Outlaw, 2009). The literal groundbreaking of the SSW became groundbreaking history as the Tate-Turner-Kuralt building became the first academic building on UNC's campus to bear the name of a Black person (Outlaw, 2009).

The public and historical examples of the School of Social Work's inclusion of Black people from students to administration are evidence of a foundational commitment to diversity and the continued presence of individuals from diverse backgrounds within the School; however, history and publicized images of diversity and inclusion have not translated to the present institutional structure, resulting in anti-Black racism being exemplified within the current, student-facing stance of the SSW.

\section{The Internal Face}

As with any institution, the public representation of the SSW differs from its daily, inner workings; however, when an institution's image of diversity and inclusion runs counter to its private, internal commitment to racial equity, tension can arise and overflow into the public eye. Two examples of this public-private disparity at the SSW exist within the very same historical markers of the School's promotion of racial equality: the hiring of Mrs. McClinton and the deanship of Dr. John B. Turner. According to Graham (2016), Mrs. McClinton's hiring at the SSW appeared to be unpublicized with little to no record of her hiring within UNC archives. Graham (2016) went on to state that Mrs. McClinton's notable employment as the first African American faculty member at UNC had very little coverage in comparison to the admission of the first Black undergraduate and graduate students in the 1950s "which came after lengthy court battles and were well covered in the 
local media" as well as when UNC hired English professor, Dr. Blyden Jackson, as the first Black full professor in 1969, "[who] was the subject of a feature story in the Daily Tar Heel" (para. 6). It should also be noted that recognition by the university of Mrs. McClinton's role in desegregating UNC did not take place until 2016-32 years after her retirement-in the form of a scholarship in her name and coverage of her story (Graham, 2016). On the other hand, the historic appointment of Dr. John B. Turner as the first Black dean at UNC is well documented, including in the naming of the SSW's building, yet a public-private disparity in racial equity is evident in the extreme lack of racial diversity among the School's leadership since Dr. Turner's retirement in 1992. Within the School's 100 -year history, Dr. Turner is both the first and only Black dean or dean of color in the SSW.

The internal-facing stance of the School also reveals a lack of racial diversity and, to a greater degree, instances of anti-Black racism experienced among students, staff, and faculty. A lack of racial diversity is evident in the underrepresentation of Black people among the student body and faculty, including tenured professors; homogenous racial identities of the authors of assigned textbooks and readings; a dearth of racially diverse guest speakers; and limited course curricula dedicated to racial justice and the study of communities of color using a strengths-based perspective. As the lack of racial diversity in the School is evident through the absence of Black representation, anti-Black racism has become evident through the presence of racist interactions among students, between students and faculty, and, in particular, within interactions between students and administration. The interviews conducted with former student activists in the School for this article provide context for UNC's SSW recent history and current occurrences of antiBlack racism in the face of a public assertion that the School "value[s] the individual differences and perspectives of each person...[and] respect and honor the lived experiences within our community" (UNC School of Social Work, 2021a, para. 2).

\section{Centering Student Voices}

In this section, we center voices of MSW and doctoral students whose activism and commitment served to greatly advance the anti-racism development of the School. One interview was conducted with "Peter," a white male MSW program alum who actively helped lead social activism efforts within the School during his time as a student from 2013 to 2015. Peter, who also attended UNC-Chapel Hill as an undergraduate student from Fall 2009 to Spring 2013, described the institution as "not being new" to him as his initial activism began with the student-led protests against Silent Sam-a monument erected on the campus of UNC-Chapel Hill in conjunction with the Daughters of the Confederacy in 1913 (nearly 50 years after the end of the Civil War) to recognize students who left the institution to fight for the Confederacy.

A second interview was conducted with "Leslie," a Black, female MSW alum from 2018-2020. She was also an undergraduate at UNC and spoke a lot about the anti-Black history of the university from its very foundations: "Black students were not admitted, not welcomed, barred from being on campus, our very foundation, because the School of Social Work is part of UNC, embedded in anti-Black narrative." Leslie's work started internally 
facing with conversations in classrooms. She described how it was first uncomfortable to name what this is (anti-Black racism) but then other students started speaking up, saying "we also need to name what it is." She talked about how "We always tip toe around to be sensitive to white feelings, but this is happening."

Additional insights about the School's anti-Black racism were provided by a coauthor, who was a student activist during her time in the doctoral program from 2012 to 2019 following the completion of her master's degree at the School. Similar to Peter and Leslie, the co-author attended UNC as an undergraduate and graduate student, which provided her with perspective on the external- and internal-facing stances of both the SSW and the larger university on issues of race and racism. The added role as a doctoral student extended her time in the School and, in turn, her participation in activism efforts, providing a bridge between Peter and Leslie's periods of enrollment.

\section{Ferguson, Silent Sam, and Deans' Responses}

Both alums talked about their activism in relation to social movements against antiBlack racism, and dean and administration failures of leadership in response to those social movements. After completing his undergraduate degree and entering the MSW program, Peter cited that his participation in student activism, and more specifically, student organizing against anti-Black racism at the SSW, was incited by two events in August 2014: the shooting murder of 18-year-old Michael Brown Jr. in Ferguson, Missouri; and the email response to the nationwide coverage of the shooting from the dean at UNC Chapel Hill's SSW. First, national outrage was ignited after Michael Brown, an unarmed Black teenager, was killed and left in the street for four hours after being shot in the back by White police officer, Darren Wilson, on August 9, 2014 (Associated Press News, 2019). Local and national protests followed Michael Brown's killing as demands for justice were made across the country, including among students at UNC-Chapel Hill. As Peter reflected on how "we had Ferguson," he described the context in which his activism took place in the SSW: "[it was ] a remix of white supremacy and violence and reflecting like, it was the Obama administration, it wasn't the Trump administration. It wasn't Amadou Diallo. That was a couple generations before, but again, it was this reframe but it was there." In efforts to quell the growing sense of unrest at the SSW, the dean sent out an email to students, staff, and faculty that stressed "tempered" responses, a need to "provide legal due process and appropriate investigation," and likened the shooting of Michael Brown to a prior high-profile racially-charged investigation that involved the Duke University Lacrosse team, in which the " "facts' turned out not to be 'fact'." In addition to these statements, the dean also called for recipients to "focus on the institutional and structural issues of racism, poverty, lack of opportunity, and exclusion" rather than on the "immediate injustice of the shooting death of Mr. Brown." The dean then ended his email reminding students, staff, and faculty that there are other issues of oppression occurring across our country, including "dramatically increasing anti-Semitism" (J. Richman, personal communication, August 19, 2014).

As Peter recalled the dean's email, he remembered it being a "microaggression" and perceived the dean as displaying the notion of "friend of all is a friend of none." Peter also 
recounted the response of other students including the co-author, who reacted by sending an email to the dean and coordinating a meeting with the dean and her faculty advisor to discuss the harm the dean's email inflicted on Black students. They also posed some next steps to move towards reconciliation and healing within the School, including a follow-up email (crafted with help from the co-author), a community dialogue within the School, and racial equity training for faculty, staff, and students: "the email came out and [co-author is] like 'hey, that hurt, what can we do?' Like from a position of togetherness." Peter went on to further reflect on the dean's response to students' responses to his email:

The dean, at that point, had sparked a broader community response, like 'wait a minute, he's digging in'... the digging in around that led to this broader activation of the community of students about what the institutional racism at UNC-Chapel Hill broadly and at the School of Social Work was.

National demonstrations of racial violence against Black people and inadequate responses from the School's leadership continued to spark student advocacy and activism in the following years with later cohorts of social work students.

Leslie was an MSW student during a heavy period of student and community activism to remove the confederate statue from campus. While ostensibly erected to honor the students who served in the Civil War, the statue, known as Silent Sam, was not erected until 1913 in an effort to reinforce Jim Crow segregation and terror (Killgrove, 2018). Protests against the statue began in the 1950s when Black students were first admitted to the University. This activism led to the statue finally coming down just before school started in August 2018 (Stancil, 2018). This led to additional organizing and activism around the disposition of the statue, including a recommendation from the University's Board of Trustees (BOT) to create a place for it in a campus location historically home to Black students (Harris, 2018). In Leslie's words, the School held a meeting to:

talk about how we were going to wait and see, partner with them, help shape the narrative, acknowledge the truth, I got worked up, really, we are going to wait and see? I asked the dean if he would make a statement against this. And he said no because he was speaking not just for himself but for the whole School. But wait, why are you a social worker? Aren't we against racism?

\section{Student Activism and Leadership}

As evident in Peter and Leslie's descriptions, racist events happening on campus and beyond motivated students' activism. Leslie related:

[Before school started] I did the summer bridge class for Black and brown students - they mentioned Silent Sam and students were like really, that's here? I learned early on at UNC, having been at protests, not feeling protected at all, police were protecting the KKK and not students. People came with bats and police did nothing. Friends having experiences with Silent Sam - and being in the School of Social Work with a wait and see attitude - we are just going to have to do this ourselves. Some faculty offered and asked how they could help...[Two other Black, 
female students] also wrote a letter addressing the things they saw in the School that they thought weren't going well. Seems like some of that is being addressed.

Similar to Leslie, Peter also described his call to participate in student activism as a responsibility to merge those internal and external faces of the School and embody the guiding values of social work: "I don't think we would have done what we did as a trio, as a larger group of students, as a school, if the institutional defensiveness hadn't reared its ugly head." Additionally, Peter explained,

...we come in with a social justice mantra, we have classes that talk about the history of oppression and liberation, we're in field placements where if you don't have an analysis of race and racism, or sex and sexism, or class and classism, you're going to be missing a lot.

In the 2014-2015 academic year, a coalition of concerned students from various racial and ethnic backgrounds, ages, and institutional positions (i.e., advanced standing, twoyear, three-year, $\mathrm{PhD}$ ) led and facilitated student activism, which culminated in partnerships with other campus offices for the planning and implementation of two community dialogue events, several debriefs, and the presentation of student-formulated measurable steps toward racial equity at a faculty meeting. Student activism was impacting the School's climate, however the push for racial equity did not come without pushback and obstacles.

Barriers. Leslie identified two primary barriers to change during her time at the School: Communication and transparency. There have long been challenges in communicating across groups at the School, which creates a disconnect between who has information and who doesn't, who is included and who isn't. Leslie shared that "the engagement piece is hard - Black and Brown students are just tired. I have to go and bare my soul and hope that you have compassion; that is mentally exhausting." In addition, with students doing so much of the labor to disrupt white supremacy and demand accountability, institutional memory becomes a barrier with most students only in residence for 1-3 years. Leslie related some of her and her colleagues' efforts,

In the Black Student Caucus we were trying to gather and save information. We need a remembrance space to keep these memories. Then COVID-19 happened and our time present was cut short. PhD students are even more not a part of the loop.

The major barriers identified by Peter centered on power imbalances within institutional positions. First, Peter pointed to demanding student schedules functioning to dissuade student activism. With limited time to engage in the strenuous work of activism, students who may have been concerned about anti-Black racism among the School's leadership had to decide if they wanted to actively participate in the fight for racial equity. This decision led to the designation of leaders among the student body who represented the interests and voice of students among School administration. Peter shared the pressure he felt from other students while leading activism efforts in the School:

There's some pressures, there's some barriers to organizing because you have a lot of demands from family, from your work life, from your field life, from the 
academic rigor of that program. ... [T] here [were] three of us... and we became like the representatives of that group. So, you have the huge student population, our group of concerned students didn't speak for everybody or was a subset, and then we became a subset of the subset but at least from that meeting, it really was, 'hey, we're concerned, yea we trust you, and y'all can do it'....It was a sense of, at least for me, basic duty. It was like.... you need to step up. People are asking someone to step up.

Peter went on to describe the power imbalance among staff and faculty as those without tenure had an inability to publicly support students and participate in social activism. Peter stated that some staff and faculty who may have been committed to anti-racism work were unable to stand with students because "they're not tenured, we're an at-will [employment] state" and some of those faculty and administrators in the School who had more power "closed ranks" around the dean, demonstrated similar defensiveness, and, in turn, decided "we're not listening to students." Peter also acknowledged the surveillance faced by faculty at a public institution, recalling previous threats from North Carolina's General Assembly following the publication of the School newsletter displaying pictures of social work faculty at a Moral Monday protest. Therefore, one's ability and desire to promote racial equity in the School greatly depended on one's position of power, which Peter related to social workers' professional relationship with clients:

I think of the power dynamics: social worker, client. Social workers are gonna have power-you need to be listening to and centering the client. School of Social Work: a lot of power in the institution, like hierarchies of staff are different. And students. There's this interesting view that like 'well students have all the power, you just see them as customers, and the customer is always right'. We don't have power compared to the people who award degrees. I think there's almost this dual perspective that the other side had more power. Structurally, we weren't talking about power. There may have been more freedom to say or do certain things but in a power analysis, we were the clients.

Unlike Peter and other MSW students, the co-author, who also participated in student activism, was a doctoral student with a longer period of time to engage in advocacy efforts and, in turn, a longer period of time to encounter barriers to the promotion of racial equity and justice in the School. One barrier faced by the co-author was discontinuity in coalitions as students cycled in and out of the MSW program throughout her enrollment. Because of the vast difference in the lengths of matriculation between MSW (e.g., 1-3 years) and doctoral students (e.g., 5-6 years; CSWE, 2018), the co-author was unable to coordinate with a consistent group of student advocates in the MSW program, leading to a rehash of issues identified by previous students; a halt to activism efforts with the graduation of MSW student advocates; and, a lack of follow-through with administration to ensure accountability to commitments made to students as well as to staff and faculty. This lack of continuity in student presence contributed to the co-author, at times, leading individually on issues of anti-Black racism particularly within the doctoral program, including publicizing the lack of Black student enrollment, dearth of doctoral curriculum focused on race and racism, and the absence of Black faculty teaching in the PhD program (Watkins, 2017). 
The role of being a doctoral student also presented various barriers to activism for the co-author. First, as indicated by Peter, student activism requires a substantial time commitment. This commitment may be particularly taxing for doctoral students, who tend to be older than MSW students with more family and financial obligations (CSWE, 2018). Second, because support from faculty and positive interactions within the departmental environment are significant predictors for successful dissertation completion, student activism can carry heavy consequences for doctoral students (Liechty et al., 2009). By challenging the structure and critically analyzing the racial climate of the School, the coauthor's relationships with administration and some faculty were negatively impacted, potentially hindering her progression in the program. Last, activism within one's academic institution as a doctoral student may negatively influence postdoctoral employment as challenging racially unjust program policies and practices may be perceived as the breaking of the "unwritten rules of graduate school" (Jones et al., 2013, p. 327). By breaking those unspoken rules, doctoral student activists who are on the job market may be viewed as difficult troublemakers with a propensity for conflict-characteristics that are not typically sought in candidates for employment. Despite these barriers and challenges, the co-author and the interviewees were able to identify some wins that sprouted from their advocacy efforts.

Wins. In the face of the challenges he experienced while leading students in efforts to promote racial equity, Peter was able to report both immediate and distal wins. First, Peter considered gaining entry into a faculty meeting to present students' proposals for social change as an immediate fruit of his labor. Peter described that experience and the resulting sense of self-efficacy in the following way:

I imagine that there's a process. I don't know how often students get to do that. So that idea of a self-empowerment tradition in social work.... We did something that wasn't a part of the structure, we organized ourselves, and we demonstrated selfefficacy. So, our own sense of self, and sort of being paralyzed like 'oh my god, the news, there's tanks in the streets, there's people getting killed'. Well you can do something about it. So, there was that internal win.

Peter also considered the relationships he developed with fellow student activists as a win. As he reflected on the students he developed relationships with as a result of their shared commitment to countering anti-Black racism, Peter described "forg[ing] this fire around anti-racism across gender, and across race, and across professions," in which the very principle of valuing human relationships was modeled and practiced.

Despite being disconnected from the School since his graduation in 2015, Peter has been able to witness more distal wins through his connections with current students and their activism around other social injustices. Peter highlighted the anti-oppressive advocacy students demonstrated in the School around the passing of HB2 by the North Carolina legislature, which required individuals to use bathrooms and locker rooms that corresponded with the sex one was assigned at birth, discriminating against transgender and gender nonbinary individuals (PBS, 2017). Peter also cited the School's recent response to the murder of George Floyd as a distal win stemming from the activism of students in response to the murder of Michael Brown: 
I don't know if [the dean's] email would have looked like how it looked like with George Floyd and this administration, in this resurgence of white supremacist violence. It's almost like this spiritual win. We as students made a commitment to values and did what we needed to do at that time because now there's this time.

The biggest win that Peter mentioned was being remembered and the implications it has for the social issues he was fighting against and those that are being fought for now:

We are connected to our ancestors of students.... if our pressure hadn't been applied in the way it did. Institutional knowledge includes institutional memory of 'oh yea, those students in 2014-2015; remember what happened then? Maybe we should ask these questions.' I think the institution remembers us, and that's a win. Which means they remember Ferguson. They remember Mike Brown. So, I think Breonna Taylor is going to be remembered this time around. Ahmaud Arbery.

Leslie described a number of positive changes at the School as a result of student organizing, many very recent. She shared a lot about the move of the Confronting Oppression course (501) from the Spring semester to the Fall semester:

Hearing about all the changes this upcoming year [was a win]. Especially how the 501 class is moved to the fall - some people may not have been exposed to this [content - Confronting Oppression and Institutional Discrimination] before. Black students come in with hope and then by the $2^{\text {nd }}$ semester mourning not getting what they expected. [There is a] dance that has to be taken - who is teaching these classes? What are my options? Where are the other Black students going to be? 501 is not a class where you want to be the only Black student. I shouldn't have to be the teacher in that class.

She also described other ways that explicitly anti-racism content has been infused into the School's curriculum, including embedding Critical Race Theory across the curriculum and an all-School read of Jonathan Metzl's Dying of Whiteness - "Those pushes were because of student activism!"

\section{Hopes for the Future}

The materialization of social activism into actual change may be delayed or denied; however, activists continue to engage in the work. Peter and Leslie both expressed hopes that their activism will eventually contribute to institutional change at the SSW. Peter voiced that he hoped his advocacy efforts would contribute to "institutional transformation" in the form of racial equity being evident among students, faculty, and administration. First, Peter hoped that students of color could move from surviving to thriving in the SSW environment:

I want students of color, in particular, to feel like they have a voice and their degree isn't just like 'shit, I gotta come in here and survive in this predominantly White institution, survive the racism, and get out with the least amount of scratches I can. 
Additionally, Peter stated that he hoped for greater levels of allyship among White students in order to reduce the psychic and physical trauma experienced by students of color through frontline advocacy and taking on the burden of addressing anti-Black racism in the School.

Next, Peter shared that he hoped that both faculty of color and scholarship around issues of race, racism, and anti-racism practices would become more present in the School. This promotion of racial equity in both the presence and substance of faculty would then contribute to racially equitable curricula, diversification of School leadership, and increased efforts to connect with historically Black colleges and universities (HBCUs) in the area rather than partnerships primarily being sought with the nearby historically White private institutions.

Overall, Peter expressed a hope for the School's private face to more closely align with its public face. Peter voiced a desire for the School to model and integrate its mission within its policies and practices, including hiring practices, policies on engagement in social activism, and admissions processes. There is also hope for efforts to repair the harm caused to students, staff, and faculty of color by first acknowledging the harm and then implementing safeguards to prevent those harms from happening in the future.

Our second MSW graduate expressed the hope that future students of color won't have to experience what she experienced. She also found that some white students in her cohort talked about holding each other accountable: "What they need to do to increase their own learning - hope this learning/approach continues - accountability for white students, faculty, too." Leslie also shared her hope that the administration be fully involved and integrated, which has to happen to move us forward.

We need to be loudly transparent - we come off as elitist and hypocritical. How can we say, "you need to do this," if we need to do that? Get to the place of what are we going to say, not if... Example for students to follow - how can I respond as a social worker to support my clients, community, model responding compassionately and quickly.

\section{Where We Are Now}

Multiple action steps have been taken over the past year that have carried forward work conducted by those students, faculty, and staff who have come before us, detailed above, and also ushered in new ideas that have been born out of the SSW, as well as the institutional, state, and national landscapes. Community members within the UNC SSW envision this work as needing to happen at multiple levels simultaneously. Over the past year many members of the SSW community involved in planning and action in the School have begun to refer to these work levels as "buckets." The three distinct, yet related buckets we are using as a framework are: 1) Work within the SSW. This work entails actions and strategies taken in the SSW to integrate antiracist practice to effect change in teaching, research, School culture, interpersonal relationships, infrastructure and policy; 2) Work that SSW community members engage in at the University level. This work includes actions and strategies taken by SSW faculty, staff, and students as we interface with the larger University to integrate antiracist practice to effect change in teaching, research, 
School culture, interpersonal relationships, infrastructure and policy; and 3) Work with the external community. This work looks like taking part in opportunities to connect the School community to advocacy and actions outside of the SSW and the university, including local, state, national, and international work. This would be building on what is already being done in the community and finding ways to connect, collaborate, amplify, and utilize our resources and person-power. The vision among members of the SSW community actively working on these efforts is that the SSW embarks on a process of self-reflexivity, truthtelling, and action that starts within our own walls, keeping our own journey toward antiracist practice central to all of our efforts. Here we will focus on two aspects of our internal work as a School community: curriculum shifts, which was described briefly above in the student voices section, and internal calls for accountability and action.

\section{Curriculum Shifts}

An important star in the constellation of change within the SSW, couched within the bucket of our internal work, has been an overhaul of one of our generalist courses: Confronting Oppression and Institutional Discrimination. This course meets CSWE requirements related to understanding how systems of oppression marginalize vulnerable populations and how social workers can act to interrupt discrimination. Prior to this academic year, Confronting Oppression had been a required course in the second semester of the first MSW year. The strategic re-envisioning of this course to ensure that it both sets a practical stage for curricular content throughout the program and sends a clear message early about the priorities of the SSW included moving the course to the first semester first year. This course works to introduce students to theoretical frameworks to prepare them for two years of antiracist and anti-oppressive pedagogy and situates itself as a way to use theory to excavate the challenges and possible solutions to societal inequities. Critical Race Theory (CRT; Bell, 1995) is a springboard to explore the multi-faceted, complex, and urgent realities of how identities impact one's lived experience. The course moves through a critical assemblage of topics, including Disability Studies, Queer Theory, Freirean Dialogic, and Environmental Justice, to interrogate the intersectional relationships between race and other forms of oppression.

As a curricular companion and as a community-building activity, the SSW instituted a Summer Reading Initiative. The selected book is intentionally woven throughout course content for both 1st and 2nd year MSW students and is the centerpiece of a faculty and staff book discussion group. Additionally, a future plan is to create year-long events that also directly connect to the chosen reading. The summer reading for 2020 was Dying of Whiteness by Jonathan Metzl. Metzl's book provides a helpful framework for faculty, staff, and students to together explore the ways that white supremacy gets enacted through institutions, public policy, and human behavior. Specifically, Dying of Whiteness provides the SSW with a lens through which to view and interrogate the insidious nature of white supremacy, a theme that we can then explore in courses ranging from policy to research methods to human development. 


\section{Internal Calls for Accountability and Action}

While the explicit curricular changes mentioned above speak to an evolution in praxis, these shifts are inextricably connected to internal calls for accountability and action made by multiple sub-groups within the SSW community over many years. In an effort to share a snapshot of the most recent actions that have propelled change, we focus on two open letters addressed to the SSW and beyond: one from students and one from faculty.

In November of 2019, MSW candidates wrote an open letter to Deans of the SSW asking for leadership from the School in taking action against anti-Black racism in the School, the University, the profession, and the country. One of the driving forces behind this open letter was the toppling of the confederate statue known as Silent Sam, and the ensuing legal battle that included an initial payout of $\$ 74,999$. and the creation of a $\$ 2.5$ million trust from the UNC Board of Governors to the North Carolina Sons of Confederate Veterans, a neo-confederate group headquartered in Tennessee. The initial payout by the UNC System to this group to take possession of the statue ignited strong opposition from faculty, staff, and students on campus (Sheehey, 2020). Among other things, the open letter from MSW students urged leadership within the SSW to step more fully into the vocal resistance movement building on campus. This letter prompted the creation of a series of working groups called Community Conversations, now partially rolled into the work of the pre-existing, student-led Social Justice Action Collaborative (SJAC). The SJAC collaborative is an open working group of faculty, staff, and students committed to working toward social justice in the SSW in both the explicit and implicit curriculum through events, actions, and collaborations.

In June of 2020, four Black-identified Full Professors in the SSW penned a Joint Statement to the entire SSW community detailing the historical and current racist harms committed by both the SSW and the Academy as a whole. The Statement included a sixpoint plan as a starting point to uprooting racism in the SSW and introduced the creation of two new working groups in the School: The Anti-Racism Task Force and Reconciliation Standing Committee. The Task Force will coordinate with ongoing efforts and activities in the School while The Reconciliation Standing Committee will serve as a sounding board and potential advocacy group for faculty, staff, and MSW/PhD students who experience racism in the School. These two groups will provide much needed leadership, oversight, and accountability for the many co-occurring projects, curricular changes, and efforts going on with the School.

\section{Conclusion}

Efforts to address racism and white supremacy in academic spaces require sustained activism that seeks to expose how racism is embedded within the fabric of our institutions. The work to address white supremacy carried out in the aforementioned school of social work required individuals at the administrative, faculty, staff, and student levels to take seriously the need for intentional dialogue and action designed to call attention to the ways in which members of the School community failed to demonstrate a commitment to antiracism. Furthermore, student activism played an essential role in holding the School's 
administration accountable for developing a plan aimed at centering anti-racism. The collective effort of students across multiple cohorts coupled with consistent advocacy from numerous faculty laid the groundwork for our School community to take tangible steps toward building and maintaining an antiracist program of action. Going forward, we will implement a process evaluation to better understand how the past and current antiracist leadership of students, staff, and faculty have led to changes in reputation, enrollment, and on-going anti-racism progress.

Any efforts to address institutional racism must insist on a multifaceted approach; one that asks the entire School community to make a commitment to behaviors and actions that center anti-racism. Social work programs committed to anti-racism must interrogate why so many voices of the past were not ceded to in their calls for justice both in their schools and in the profession. To answer this with integrity, faculty and administrators must name the role that white supremacy as a system plays in the academy and in the social work profession. Additionally, those in the highest positions of power must be earnestly willing to center the voices and experiences of minoritized students who have been actively harmed by the School environment by creating participatory change processes. Author and activist Tema Okun (1999), writing for the organization Dismantling Racism Works, writes, "Culture is powerful precisely because it is so present and at the same time so very difficult to name or identify" (p. 1). The dismantling of deeply embedded ways of knowing and acting is difficult yet urgent work. We have seen a culture of white supremacy creep into the very work discussed in this article, centering whiteness and unwittingly reproducing anti-Blackness due to the strength and compulsion of dominant culture to become the default without careful attention to this toxic pattern. Our School's current mission, "Advancing Equity, Transforming Systems, Improving Lives," provides a mutually agreed upon springboard for this vital work moving forward as both a School and a profession (UNC School of Social Work, 2021b).

The primary limitation of this article is that case study methods are not generalizable to other contexts. This paper addresses only one school's experience in the US South, as well as centering the experiences of former students who were integral in affecting change at the School, in an effort to elucidate the historical context of our journey and to shed light on the very real fact that doing this work with integrity is a marathon and not a sprint.

Schools committed to combating white supremacy must build their own springboards, doing so with a recognition that the work never ends and will never be perfect. To be clear, the goal should not be perfection but rather an unwavering commitment to ensuring that anti-racism permeates every aspect of the institution's practice. Anti-racism must become more than a mission statement, a committee, a task force, or a reaction to a national event; it must become who you are and who you seek to become as an institution for those who are currently a part of your School community and for those to come. So, we pose the following question to you: are you truly committed to anti-racism?

\section{References}

Abrams, L. S., \& Moio, J. A. (2009). Critical race theory and the cultural competence dilemma in social work education. Journal of Social Work Education, 45(2), 245261. https://doi.org/10.5175/jswe.2009.200700109 
Adams, K. B., Matto, H. C., \& LeCroy, C. W. (2009). Limitations of evidence-based practice for social work education: Unpacking the complexity. Journal of Social Work Education, 45(2), 165-186. https://doi.org/10.5175/jswe.2009.200700105

Associated Press News. (2019, August 8). Timeline of events in shooting of Michael Brown in Ferguson. https://apnews.com/article/9aa32033692547699a3b61 da8fd1fc62

Bell, D. A. (1995). Who's afraid of critical race theory. University of Illinois Law Review, 1995, 893-910. https://sph.umd.edu/sites/default/files/files/Bell_Whos\%20Afraid\% 20of\%20CRT_1995UIIlLRev893.pdf

Bromley, D. B. (1986). The case-study method in psychology and related disciplines (pp. 39-54). Wiley.

Clark, E. J., Weismiller, T., Whitaker, T., Waller, G. W., Zlotnik, J. L., Corbett, B. (Eds.). (2006). 2005 Social Work Congress-Final report. NASW Press.

Council on Social Work Education [CSWE]. (2015). Educational policy and accreditation standards for baccalaureate and master's social work programs. https://www.cswe.org/getattachment/Accreditation/AccreditationProcess/2015EPAS_Web_FINAL-(1).pdf.aspx

CSWE. (2018). 2017 statistics on social work education in the United States. https://www.cswe.org/CMSPages/GetFile.aspx?guid=44f2c1de- $65 \mathrm{bc}-41 \mathrm{fb}-\mathrm{be} 38$ $\underline{\text { f05a5abae96d }}$

Drechsler, K., Hessenauer, S., \& Jaber-Wilson, L. (2019). Engage in Diversity and Difference in Practice Competency: Exploring the Explicit Curriculum and Outcome Measures of Graduate Social Work Programs. Journal of Social Work Education, 56(2), 341-353. https://doi.org/10.1080/10437797.2019.1656571

Graham, N. (2016, November 18). Noteworthy firsts: Hortense McClinton. For the Record. https://blogs.lib.unc.edu/uarms/2016/11/18/noteworthy-firsts-hortensemeclinton/

Harris, A. (2018, Dec. 3). Silent Sam Survives. The Atlantic. https://www.theatlantic. com/education/archive/2018/12/unc-announces-plan-create-museum-silent$\underline{\operatorname{sam} / 577228 /}$

Jani, J. S., Pierce, D., Ortiz, L., \& Sowbel, L. (2011). Access to intersectionality, content to competence: Deconstructing social work education diversity standards. Journal of Social Work Education, 47(2), 283-301. https://doi.org/10.5175/jswe.2011.200900118

Jones, T. B., Wilder, J., \& Osborne-Lampkin, L. T. (2013). Employing a Black feminist approach to doctoral advising: Preparing Black women for the professoriate. The Journal of Negro Education, 82(3), 326-338. https://doi.org/10.7709/ jnegroeducation.82.3.0326

Kendi, I. X. (2019). How to be an antiracist. One world. 
Killgrove, K. (2018). Scholars Explain the Racist History of UNC's Silent Sam Statue. Forbes. https://www.forbes.com/sites/kristinakillgrove/2018/08/22/scholars-explainthe-racist-history-of-uncs-silent-sam-statue/\#25fd0ae0114f

Liechty, J. M., Liao, M., \& Schull, C. P. (2009). Facilitating dissertation completion and success among doctoral students in social work. Journal of Social Work Education, 45(3), 481-497. https://doi.org/10.5175/jswe.2009.200800091

Moss, G. (2015, February 27). Mrs. McClinton did not study black history--she lived it. University Gazette. https://www.unc.edu/posts/2015/02/27/mcclinton/

National Association of Social Workers. (2017). NASW code of ethics. https://www.socialworkers.org/About/Ethics/Code-of-Ethics/Code-of-Ethics-English

Okun. T. (1999). White Supremacy Culture. Dismantling Racism Works. https://www.whitesupremacyculture.info/

Outlaw, J. (2009, February 2). John Turner, former UNC dean and social work trailblazer, passes away. UNC News Archives. https://uncnewsarchive.unc.edu/ 2009/02/02/john-turner-former-unc-dean-and-social-work-trailblazer-passes-away-2/

PBS. (2017, March 30). What the North Carolina legislation to repeal HB2 bathroom bill' actually says. News Hour. https://www.pbs.org/newshour/nation/watch-live-nclegislature-debates-repeal-hb2-bathroom-bill

Sheehey, M. (2020, Feb 13). Unraveling the story behind the Silent Sam lawsuit. In The Daily Tarheel. Retrieved from https://www.dailytarheel.com/article/2020/02/silent$\underline{\text { sam-timeline-0214 }}$

Stancil, J. (2018, Aug. 20). Protesters topple Silent Sam Confederate statue at UNC. News \& Observer. https://www.newsobserver.com/news/local/education /article217035815.html

The Black Student Movement. (n.d.). Mission and history. http://www.uncbsm.com/history

The Carolina Story: A Virtual Museum of University History. (2019a, June 18). The BSM's 23 demands: December 1968. https://museum.unc.edu/exhibits/show/blackstudent-movement/the-bsm-s-23-demands--december

The Carolina Story: A Virtual Museum of University History. (2019b, June 18). Food workers'strike: February to March 1969. https://museum.unc.edu/exhibits/show/black-student-movement/food-workers-strike--february

The Carolina Story: A Virtual Museum of University History. (2019c, June 18). The Black student movement at Carolina. https://museum.unc.edu/exhibits/show/blackstudent-movement

University of North Carolina at Chapel Hill. (2020, August 1). Paving the way: Carolina's Black pioneers. https://www.unc.edu/story/black-history-month-2020/

UNC School of Social Work. (2021a). Inclusion. https://ssw.unc.edu/about/our-future/inclusion/ 
UNC School of Social Work. (2021b). Mission, vision, and values. https://ssw.unc.edu/about/our-foundation/mission-and-vision/

Watkins, C. (2017, August 27). Letter: UNC's racism includes School of Social Work. Daily Tar Heel. https://www.dailytarheel.com/article/2017/08/letter-uncs-racismincludes-school-of-social-work

Yin, R. K. (2012). A (very) brief refresher on the case study method. In Applications of case study research (3rd ed., pp. 3-20). Sage. https://www.sagepub.com/sites/default/files/upm-binaries/41407_1.pdf

Author note: Address correspondence to Travis Albritton, UNC School of Social Work, 325 Pittsboro St., CB\#3550, Chapel Hill, NC 27599-3550. Email: talbritt@email.unc.edu

Acknowledgements: We are grateful to current and former students, including Andrew Heil and Treasure Williams, for their long-term work to push us in the direction of antiracism and sharing their experiences in the School. We also want to acknowledge the ongoing leadership from Black faculty who have maintained a focus on racial justice and worked to hold our institution accountable for dismantling systems of oppression. 